\title{
Syntactic Compression in the Modern Russian Language
}

Submitted 15/02/19, 1st revision 10/04/19, $2^{\text {nd }}$ revision 26/05/19, accepted 01/06/19

\author{
Panteleev A.F. ${ }^{1}$, Redkozubova E.A. ${ }^{2}$, Agapova S.G. ${ }^{3}$ \\ Abstract:
}

Purpose: The aim of this article is on profound systematic analysis of functional syntax theory and exploring the second level syntactic compression in the Russian language.

Design/Methodology/Approach: To realize the objectives of this investigation, it seems necessary: first, to reveal the spectrum of syntactic structures; second, to determine the ways of representing the process meaning in minimized predicative structures; third, to describe the multilevel system of the means updating the propositive semantics and functionalsemantic categorie in the Russian syntax.

Findings: It was proved that the concrete noun as a result of the second level compression can act as a carrier of procedural semantics and secondary predication in a simple sentence. The authors identified the main types of structures with concrete nouns, expressing propositive semantics at second-level compression process, defined methods and means of representing the procedural meaning in the analyzed structures and established a link between second-level syntactic compression and the speaker's cognitions.

Practical Implications: The results may be implemented into the practice of teaching the theory of language, general and comparative linguistics. The materials and conclusions of the research contribute to the efficiency of oral and written communication.

Originality/Value: The main contribution of this study is to shift the emphasis from the study of the phenomenon of compression at the level of transformation of complex sentences into synonymous simple ones, to the analysis of the second level syntactic compression and accumulation of a noun with a specific semantics of procedural meaning.

Keywords: General and comparative linguistics, compression, language economy, functional syntax, propositional semantics.

JEL Code: Z13, Z19.

Paper Type: Research article in Special Issue dedicated to Russian Economy.

Section 6: Linguistics.

\footnotetext{
${ }^{l}$ PhD in Philology, Associate Professor, Head of the Department of Russian Language, Institute of Philology, Journalism and Cross-Cultural Communication, Southern Federal University, Rostov-on-Don, Russia, afpanteleev@sfedu.ru

${ }^{2}$ D.Sc in Philology, Professor of the Department of English Theory and Practice, Institute of Philology, Journalism and Cross-Cultural Communication, Southern Federal University, Rostov-on-Don, Russia, eredkozubova@sfedu.ru

${ }^{3}$ D.Sc in Philology, Professor of the Department of English Theory and Practice, Institute of Philology, Journalism and Cross-Cultural Communication, Southern Federal University, Rostov-on-Don, Russia, agapova@sfedu.ru, scopus authid 57204125105
} 


\section{Introduction}

Compression is a universally valid phenomenon in many modern languages, manifesting itself at every level of a language system. There are different kinds of linguistic compression (lexical, semantic, phonetic), as well as various ways of information compression - reduction, assimilation, ellipsis, acronymy, telescopy, syncretism, use of metaphors and metonymy, use of foreign words and nonassimilated borrowed components, etc. Syntactic compression as a realization of the linguistic economy principle in the Russian language is primarily manifested in the compression of composite sentences, their transformation into synonymic simple sentences with semi-predicative constructions or with abstract nouns, expressing propositive semantics. Syntactic compression, connected with the transformation of a composite sentence into a synonymic simple one with an abstract noun in the function of a secondary predicate, is quite thoroughly investigated in linguistics.

However, it is appropriate to treat the following type of an utterance compression as a syntactic compression of the first degree, since a concrete noun may be characterized by procedural semantics. Constructions with concrete nouns expressing propositive semantics are regarded as examples of a higher degree of an utterance compression, i.e. syntactic compression of the second degree. Syntactic compression of the second degree is typical of the Russian language, but this phenomenon has not received enough attention in modern linguistics.

\section{Literature Review}

The concept of compression in linguistics can have different values and meanings. The analysis of existing works on the investigated problem shows that compression can be considered and studied from many and diverse viewpoints.

Both domestic and foreign linguists have been interested in the problems of language economy since long. One of the first scholars to study the problem was P. Passy (1890). Besides P. Passy systematic study of linguistic economy was also done by H. Sweet (1888), who considered the compression phenomenon at a phonetic level. Passy distinguishes two core messages, first of which states, that a "language constantly strives to dispense itself from what is excessive" (Passy 1890, p. 227), and the second "the language constantly emphasizes what is essential" (Passy, 1890, p. 228). Bally (1955) reasoned about economy of human efforts and simplification of linguistic forms. Martinet (1960), who, using extensive language material, developed the idea of human aspiration to bring his/her mental and physical activities to the minimal extent possible, considered, that "language evolution is determined in general by a permanent controversy between human needs to communicate and to express his/her ideas, and the aspiration to minimize mental and physical activities... hence, linguistic behavior is regulated by the principle of least effort". Herewith Martinet (1960, p. 370) stresses: "The term 
'economy' includes everything: elimination of useless distinctions, development of new distinctions, and maintaining of status quo. Linguistic economy is a synthesis of applied forces".

The tendency to speech efforts economy is acknowledged to be a universally valid development factor of languages of different systems. Admoni (1955) treated the economy of speech efforts in grammar, Peshkovsky (1956) in dialogical speech, and Polivanov (1981) found the cause of linguistic economy in "human idleness". Language compression is obviously based on the rules of communicational behavior, formulated by H. Paul Grice (1975). These rules appeal to evade from every excess information load, and at the same time recommend to include the volume of information, which is necessary to execute current goals of a dialogue. During the process of communication a speaker is guided by two main aspirations: aspiration to "optimize the language code", which is implicitly related to the expansion of the system, on the one hand, and on the other hand-aspiration to "economize efforts" (Pronina 1973, p. 123-130). It is clearly seen in colloquial speech, which is characterized by the following peculiarities: participation of a companion; situational precondition of communication; speech spontaneity; expressiveness and emotionality.

Study of economy in modern linguistics is fulfilled mainly in word-formation and syntax (Redkozubova 2004; 2013; Panteleev 2010; 2018). The tendency to economy is one of the main reasons for active processes in a language system, so it is the cause of language development and its evolution. There are two approaches to the problems of language economy: broad and narrow. According to the broad approach, any language phenomenon, in its synchrony and in its diachrony, is economical, which causes dissolution of new forms and development of language as a means of communication. Narrow approach is of qualitative nature, as it is based on the variation of language means, where at the linguistic means are replaced by more economical units. Broad understanding is applied to language as a system, and narrow to speech (Zimina, 2007, p. 11; Tikhomirova and Mileyeva 2008, p. 212).

Hence, the language economy principle manifests itself in the fact, that a speaker selects language means, by which he/she starts communication. In the process of this selection, among the multitude or great variability, the principle of economy is of great importance as it allows enclosing capacious content into a short, laconic form. The economy of linguistic means is not only the economy of efforts on the part of a speaker, but also a tendency aimed at fast and clear understanding of information by a listener. It is a result of modern society's need to increase informative volume of the text at the sake of its structural downsizing, as well as the need to economize printed product and time of messages. As any oral message is expanded in time, and time is inconvertible, a message must be limited in its length, i.e. the choice of a word or grammatical structure must be done within the shortest period of time. A speaker chooses common, brief, frequent words and grammatical structures, which require less effort. 
The problem of information compression is broadly represented in modern literature. Majority of researchers understand linguistic compression as the possibility to express a certain volume of information with the help of minimal, laconic language means. The result of linguistic economy is briefness, which anticipates structuralsemantic density of an utterance, which possesses minimal formal structure and maximal (optimal) semantics (Zimina 2007, p. 12). Linguistic compression develops as a specific linguistic phenomenon, when "there is a possibility to reduce a certain portion of a text without any considerable loss for its content" (Litvin 2003, p. 2). One of the main manifestations of compression in syntax is compression of complex sentences, and their transformation into such simple sentences, which are designated as polypropositional (Zolotova, Onipenko and Sidorova 1998) or non-elementary (Tcheremisina and Kolosova 1989), containing a secondary nominal predication within its composition.

The secondary predication issues are in the focus of attention of modern linguistics. Special interest is given to the non-elementary simple sentences with abstract nouns, functioning as bearers of propositional meaning, "second" message in a sentence, which is simple from the point of view of traditional grammar. Adamets (1973; 1992), Alisova (1974), Pereverzev (1996) consider that an abstract noun deverbative, i.e. any noun, formed from the verbal stem, is acknowledged to be the most typical means to express secondary predication in a polypropositional simple sentence, along with an infinitive in the role of a "second" message- bearer.

However, this type of compression of an utterance is, from our point of view, the manifestation of the first grade of compression. At the same time in Russian there is a second grade of compression, related to the possibility to express propositive meaning by a concrete noun associated with elimination of the noun with procession semantics. Similar constructions are regarded as a new level of compression, a higher level of an utterance compression.

\section{Research Methods}

The research proceeds from general scientific methods, methods of logical and historical approaches, analysis and synthesis, methods of comparative, transformational, structural, semantic analysis using methods of collecting the data needed.

\section{Results}

One should distinguish the second grade of compression, related to representation of procession meaning by non-prepositional word forms of concrete nouns, and the second grade of compression, represented in the prepositional-nominal word forms of concrete nouns. The non-prepositional word-forms of abstract nouns represent a relatively small number as compared to the prepositional-nominal word-forms of 
abstract nouns - bearers of propositive meaning. Same regularity is observed in the use of concrete nouns in the function of the means of expression of secondary noun predication in a "non-elementary" simple sentence. Their prepositional-nominal word-forms are much more frequently used; however, it is worth mentioning, that the use of a concrete noun without preposition in the function of a "second" message-bearer is pretty regular in the language of fiction, journalism and colloquial speech.

Analyzing the non-prepositional word-forms of concrete nouns, used in the function of second predication bearers, it should be noted, that most actively used among them are concrete nouns in the form of genitive case Semantics of the main predicate actualizes processual meaning of dependent word-forms, as the verb supposes a certain presumable situation available, expected action, referred to future perspective. The word-form of a concrete noun does not possess the semantics of process in its meaning, but elliptically it denotes a proposition. Besides the complex sentence with homogeneous clauses, there is a simple "non-elementary" sentence with explicated concrete noun, synonymous to construction under investigation. In these constructions the situation is already completely denoted, in contrast to the sentence with a concrete noun, where the availability of the situation itself is denoted in the word-form of a concrete noun. This confirms the idea, that constructions with concrete nouns are more closely connected with the context and speaker's background knowledge as compared to abstract nouns and extended verbal analogues.

The analysis of our actual material allows to state that tha abstract and concrete nouns being homogenous members act as the means of actualization of a concrete noun propositive meaning. This additional way of procedural actualization within the frames of secondary nominal predication is broadly represented in the language. The predicate governs two objects in the form of genitive case without preposition. The propositional meaning of the first of the coordinated syntaxeme stresses the implicitly expressed procedurality of the second syntaxeme.

Concrete nouns without a preposition acting as carriers of secondary nominal predication have stronger connection with the context, con-situation, background knowledge of the speakers in comparison with the prepositional-nominal word forms used in this function of concrete names. The primary means of actualization of pro-positive meaning of a concrete name is semantics of the predicate of a polypro-positive simple sentence. However, micro and macrocontext means are actively used as well as constructions with homogeneous parts of the sentence abstract and concrete nouns.

An event-temporal syntaxeme can be formed using a name with specific semantics representing the event elliptically. This remark may be considered a necessary condition for consideration of structures where the proposition is expressed implicitly with the help of the prepositional-nominal form of a concrete name with 
the prepositions "after", "before". In such constructions, the role of co-empire increases, i.e. mutual information value of communicants, which allows precise interpreting of reduced predication meaning with eliminated procedural name.

Opposite from the point of view of temporal relation with main action is the action of a proposition, implicitly pronounced syntaxeme "before + ablative case" of a particular name. A concrete noun in the form of the instrumental case with "before" preposition expresses the proposition elliptically, the meaning of which is updated not so much by the predicate semantics, but by means of context and consituation. In terms of meaning, this syntaxeme is synonymous with the subordinate adverbial time in a complex sentence

It should be emphasized that the involvement of a wider context, co-empires are necessary for explication of a situation, a proposition, elliptically represented in the syntaxes "after + genitive case", "before + instrumental case" of a particular noun. The presence of a pro-positive meaning for a particular name is actualized by the semantics of the main predicate, since the designated action implies some preceding or subsequent process, situation implicitly expressed by a particular noun.

Prepositional-nominal word forms of abstract names occupy a central place among the carriers of pro-positive meanings in polypro-positive simple sentences. The same pattern is observed in use of concrete nouns in the function of means of expressing secondary nominal predication in the "non-elementary" simple sentence. Prepositional-nominal word forms of specific nouns in this function are used much more often than nonprepositional word forms.

Among the syntaxemes with concrete nouns in the function of specifiers of secondary nominal predication, constructions with the preposition "in" ("na" in russian) occupy a prominent place. Unlike combinations of specific names with the preposition "when," these structures show a closer connection with the semantics of the main predicate, context tools, background knowledge of speakers, or coempirism required for updating the concrete name with a positive value for the syntax "to + accusative case".

The nature of taxis relations in such sentences is determined primarily by the semantics of the predicate - main action. The verb "send" implies the direction of action "somewhere" that occurs after the moment of main action. The focus of the action of reduced pro-position into the future does not violate the general temporal plan of the whole statement referred to the past.

The morphological indicator of the procedural nature of abstract nouns is the use of the plural forms, showing the various manifestations of the action or its repeatability. Apparently, the use of a plural form and a specific noun has a similar function, since the polysemy of a verb, the main predicate, does not allow one to 
uniquely consider the dependent word "to + accusative" as an eventive syntaxeme. Thus, the plural form of a concrete name is a marker of the poly-positive value of these sentences, means of updating the peripheral value of the main predicate.

Concrete nouns with the preposition "in" ("na" in Russian) as a specifier of a reduced proposition are synonymous in meaning to the subordinate clause in the complex sentence. The propositional meaning of the syntax data is actualized with the help of the semantics of the predicate "non-elementary" simple sentence, context, constitution, the use of a particular name in the form of a plural, which is an indicator that the noun has a procedural meaning.

Speaking of the secondary nominal predication expressed by concrete nouns when eliminating a deverbative, it is necessary to note a closer connection of such constructions with the macrocontext, comparing them with verbal constructions and with the secondary predication expressed by the name of the action. In such cases, one should speak of the implicitness of imaginary knowledge, during which explication of the value of the secondary nominal predication does not correspond to our understanding of the prototypical situation. Establishing the nature of the lexical-semantic relations between the primary and secondary predication in such sentences is impossible without engaging the context.

Co-empires are necessary for explicating a situation, a proposition that is elliptically represented in the syntax for "accusative", "for + genitive" of a particular noun. The presence of a pro-positive meaning in a particular name is actualized primarily by the semantics of the main predicate, since the action it designates implies some previous or subsequent process, a situation implicitly expressed by a particular noun. However, the semantics of a specific name is also a means of updating the propositive value in the constructions in question. A separate group of prepositional case forms of specific names that act as carriers of the "second" message in a polypro-positive simple sentence consists of syntaxes "about ("o" in Russian) + prepositional case" and "about ("pro" in Russian) + accusative case" of a particular noun. Similar constructions are very typical for the language of fiction and journalism.

Syntaxemes "about + the accusative case" of a concrete name as a vehicle of the secondary nominal predication as well as the construction "about + prepositional case" are synonymous in meaning to a complement clause in a complex sentence, but are used far more seldom. The prepositional and declensional combinations of concrete nouns with "about" are characterized by the same features as in syntaxemes with the preposition "about." The main means of actualizing the propositive meaning of an objective noun is semantics of the predicate of the predicative basis.

The implicit utterances with the Russian prepositions "for" ("za"), "on" ("na") and "with" ("s") should best be regarded as structures with the meaning of purpose. They are also used for indicating the category of casualness. Such a subgroup of 
compound sentences occurs most frequently in the studied sources of publicist style in the last decades' literature (around 65-70\%). However, in addition to the meaning of purpose such constructions may have other meanings, which is proved by the synonymy of constructions with concrete nouns and different types of circumstantial clauses. In declarative sentences the constructions with a causative meaning are represented by prepositional and casal structures containing verbal and abstract nouns. This is natural, given that the cause is perceived as an event triggering another event called the consequence. However, in an implicit expression of the cause in prepositional-casal structures concrete nouns may also occur. These nouns, however, are not expressions of the situation which is thought of as a cause; they only define one of the situational components. So we shall consider - as implicit combinations with a causative meaning - those whose prepositional-casal model includes: 1) names of some spatially restricted concrete object; 2) persons' names. Prevalent in materials under study are examples where a name of a concrete object occurs. In such constructions the Russian preposition "from" ("ot") is used more often than others

Such constructions with a coordinating link that combines a concrete noun with an abstract one are quite common both in oral and written speech and frequently occur in works of the Russian literature of the 20th century. Particularly typical are constructions with conjunction "and". The use of other coordinating conjunctions is not so characteristic in poly-positive simple sentences of this type.

Thus, speaking about concrete nouns as vehicles of predication in elimination of a name with processional semantics, it should be pointed out that tools of actualizing a propositive meaning often interact and supplement one another. Combinations of different tools of actualizing the secondary predication meanings are quite characteristic for "non-elementary" simple sentences of this type..

\section{Discussion}

Of great interest is the problem of syntactic synonymy and of mainstreaming of the processual cemantics of a concrete noun. The performed analysis demonstrates that constructions with non-prepositional concrete nouns in the forms of genitive and accusative case are synonymous in their meaning to explicative subordinate clause in a complex if-sentence, compare: "Вечером другого дня я усльшал Васину скрипку” (V. Astafiev) - "Vecherom drugogo dnia ya uslishal Vasiny skipku” (In the evening of the other day I heard Vasya's fiddle) ".. Concrete name in the form of accusative case elliptically expresses proposition, which availability is actualized by semantics of the main predicate, implying availability of a certain process, and not of a certain object. This polypropositive simple sentence is synonymous to the following complex if-sentence, compare: "Vecherom drugogo dnia ya uslishal, kak zvuchit Vasina skripka." (In the evening of the next day I heard, Vasya's fiddle sounding.)'.Hence, the concrete noun elliptically denotes the process, related to 
sounds of a concrete object - fiddle. The process obtains its explicit expression in the explicative subordinate clause within the complex construction.

Thus, an important role is played by the correlation between semantics of a verb and a noun. The verb, its semantics, determines time reference of the combination with a noun. Noun semantics assumes the existence of the concepts of dynamics, object movement or aspiration of a subject to participate in variation of his/her psychological or physical status, and occasionally of his/her material property conditions (Panteleev (2018) in speaker's cognition. Semantics of a noun usually determines its ability of complex nomination, that of an object and process. The nomination of process is in many ways determined by con-situation, by correlation of action semantics (represented by the verb) and result-of-action semantics (represented by the noun). An intermediate action required for obtaining a result is represented implicitly.

Moreover, in the speaker's cognition there are natural links "sound $\leftrightarrow$ sound source", wherein the name of the sound source is conventionally used as a blend of these two meanings: "hear the fiddle". The verb "to hear" actualizes the meaning of sound in the word "fiddle". "Violin" is not only an object, it is also the source of sound, just like any musical instrument, or any living creature, e.g.: "I heard my father". The cognitive sign of sound is found in the semantics of objects' names and the peculiarities of this semantics serve to speech economy. In the speaker's cognition and in their attempts to economize speech and mental effort there is a certain optionality of explicit process naming while denoting the result.

Thus, the potential economy is due to the fact that in the semantics of the noun there is not only the meaning of an object, but the meaning of its functions and purposes (movement, sound, etc.). The functional meaning inherent in the semantic structure of a noun is actualized by the context, combinability and does not need any explicit, additional verbal expression ("bread knife", i.e. for cutting bread), although it is possible. A direct object with a verb is often a proposition, for filling which one should fill a semantic gap, compare: "hear the sound of a violin".

"Ellipsis is... not a "defect" of structure but its reasonable modification made in order to achieve a greater communicative effect" (translated by E. Redkozubova) (S.G. Iljenko (2008). The ellipsis of the verbal component fulfills the same function when there is a seme of action or process in the semantics of a concrete noun. The semantics is clear from the context and it is expressed explicitly. Such are the semes of moving in the nouns "car, train, bus", the semes of sound in "flute, violin, cello". It may give rise to synonymy of sentences. Particularly relevant seems the solution of the problem of choosing linguistic tools for building utterances by the speaker. This very issue needs a detailed analysis and establishment of the reasons why a speaker chooses - from a variety of isomorphic syntactic structures - constructions with secondary predication expressed by various linguistic means. 


\section{Conclusion}

Thus, speaking about concrete nouns as vehicles of predication in elimination of a name with processional semantics, it should be pointed out that tools of actualizing a propositive meaning often interact and supplement one another. Combinations of different tools of actualizing the secondary predication meanings are quite typical of "non-elementary" simple sentences of this type. Concrete nouns that perform as vehicles of secondary nominal predication are linked, in the speakers' cognitive conscience, either with condition or a certain function included in the cognitive semantics of concrete names. In elimination of an abstract name or a subordinate part of a complex sentence the processional semantics becomes actualized with a concrete noun, a vehicle of propositivity.

In the semantic structure of a concrete name there is a seme that reflects the connection of a person or a thing with that action or condition with which they closely associate in real life. This phenomenon is characteristic both of combinations of concrete names with prepositions and of preposition-free word forms of concrete nouns with processional semantics. The tools of actualizing a propositive meaning in nouns with concrete semantics, which nouns function as vehicles of secondary nominal predication, can be defined as differently leveled entities since taking part in the mechanism of explication and unfolding of the process semantics are units of not only grammatical but also lexical levels of language.

The higher degree of compression - characteristic of such constructions predetermines a closer, compared to abstract nouns, connection of concrete nouns with the context and the speakers' background knowledge. It seems relevant to focus on the problem of choosing linguistic tools for building utterances by the speaker.

\section{References:}

Adamets, P. 1992. A few notes on syntactic homonymy in Russian. Systematic semantic links in linguistic units. Moscow, pp. 46-53.

Adamets, P. 1973. About semantic and syntactic functions of deverbative and deadjektive nouns. Scientific reports of higher education. Philology, Issue 4(4), pp. 40 - 46.

Admoni, V.G. 1955. Introduction to syntax of modern German. Moscow, Foreign languages publishing house, $392 \mathrm{p}$.

Alisova, T.B. 1974. Concerning the so-called "static" predicates. All-Union science conference on theoretical issues of linguistics. Moscow, pp. 55 - 60.

Bally, Ch. 1955. General linguistics and issues of the French language. M., 416 p.

Cheremisina, M.I., Kolosova, T.A. 1987. Essays on the theory of complex sentence. Novosibirsk. 197 p.

Ilyenko, S.G. 2009. Communicative-structural nature of the complex sentence and its anthropocentric potential. Asymmetry as a principle of functioning of language units. Novosibirsk, p. 31-37. 
Litvin, S.I. 2003. Compression of a fiction text in a two-language situation: Based on materials of the English and Russian languages. PhD. thesis. M., 168 p.

Martine, A. 1960. Fundamentals of general linguistics. New phenomena in linguistics. Moscow, Foreign languages publishing house, pp. 365-565.

Panteleev, A.F. 2018. Secondary nominal predication in non-elementary simple sentence. M., Publishing House INFRA-M, p. 162.

Panteleev, A.F. 2010. Concrete noun without preposition as a vehicle of secondary nominal predication. News of the Southern Federal University. Philological sciences, issue 2, pp. 108-116.

Passy, P. 1890. Etudes sur les changements phonetiques et leurs caracteres. Paris, Publishing House Firmin-Didot, 270 p.

Paul Grice H. 1975. Logic and Conversation. In: Syntax and Semantics, issue 3, Speech Acts, ed. by Peter Cole and Jerry L. Morgan. New York, Academic Press, pp. 41-58.

Pereverzev, K.A. 1996. Semantics of causal relationship in the context of lexical and propositional typology. Issues of linguistics, issue 5, pp. 107-118.

Peshkovskiy, A.M. 1956. Russian syntax in terms of science. 7th edition. Moscow, Uchpedgiz, $511 \mathrm{p}$.

Polivanov, Ye.D. 1981. What are the causes of language economy? History of Soviet linguistics. Some aspects of general theory of language: reading-book. Moscow, Higher School, pp. 51-56.

Pronina, I.V. 1973. On the phenomenon of ellipsis. Moscow, Foreign languages. Collection of articles, issue 9, pp. 123-130.

Redkozubova, E.A. 2004. Formation of abridged nouns in American slang as realization of the principle of language economy. Works and materials of The international scientific conference devoted to the V.P. Malashenko jubilee. "Language. Discourse. Text." Part 2. Rostov-on-Don, RGPU publishing house, pp. 97-100.

Redkozubova, E.A. 2013. Slang and dichotomy of economy/redundancy. News of the Southern Federal University. Philological science, issue 4, pp. 58-66.

Tcheremisina, M.I., Kolosova, T.A. 1987. Essays on the theory of complex sentences. Novosibirsk, 197 p.

Tikhomirova, O.V., Mileyeva, M.N. 2008. Phonetic compression and its manifestation in business English. Bulletin of the humanities department of IGKhTu (Ivanovo-based State University of Chemical Technologies), issue 3, pp. 212-217.

Sweet, H. 1888. History of the English sounds from the earliest period. Oxford, Clarendon Press, 409 p.

Zimina, L.O. 2007. The principle of economy in modern advertizing. Abstract. Of PhD. Thesis, Tomsk, $20 \mathrm{p}$.

Zolotova, G.A., Onipenko, N.K., Sidorova, M.Yu. 1998. Communicational grammar of the Russian language. Moscow, 528 p. 